九州大学学術情報リポジトリ

Kyushu University Institutional Repository

\title{
On Image Database File HANABACHI Based on the Japanese Bees
}

Tadauchi, 0samu

Dawut, Ahmatjan

Inoue, Hitoshi

https://doi.org/10.5109/2653

出版情報: ESAKIA. 41，pp.149-154，2001-03-31. Entomological Laboratory，Faculty of Agriculture, Kyushu University バージョン：

権利関係 : 


\title{
On Image Database File HANABACHI Based on the Japanese Bees 1), 2)
}

\author{
Osamu TADAUCHI \\ Entomological Laboratory, Faculty of Agriculture, \\ Kyushu University, Fukuoka, 812-8581 Japan \\ Ahmatjan DAWUT \\ Entomological Laboratory, Graduate School of Bioresource and Bioenvironmental Science, \\ Kyushu University, Fukuoka, 812-8581 Japan \\ and \\ Hitoshi INOUE \\ Computing and Communications Center, \\ Kyushu University, Fukuoka, 812-8581 Japan
}

\begin{abstract}
An image database file HANABACHI based on the Japanese bees is constructed and is open to the public on Internet. Each record is composed of 16 items, i.e., scientific names (family, genus and species), Japanese name, distribution data, type locality, type depository, source of the original description, synonymy, morphological notes, remarks, flying season, visiting or associated flowers, natural enemy and images. The images include the whole body, head in frontal view, mesoscutum, propodeum, metasomal terga and so on. A home page of the HANABACHI is presented. It is managed by a management system SIGMA.

Key words: bioinformatics, entomology database, network, public use, Japanese bees, images, HANABACHI, SIGMA, Internet.
\end{abstract}

1) Contribution from the Entomological Laboratory, Faculty of Agriculture, Kyushu University, Fukuoka (Ser. 5, No. 64).

2) This work was supported by a Grant-in-Aid for Publication of Scientific Research Results and a Grant-in-Aid for Scientific Research (No. (B)(2) 09490028) from the Ministry of Education, Science, Sports and Culture, Japan and Japan Society for the Promotion of Science (Head investigator of both grants: O. Tadauchi). 
We have produced three main insect databases, KONCHU, MOKUROKU and DJI at Computer Center of Kyushu University (present: Computing and Communications Center, Kyushu University) since 1983 and have opened to the public on Internet as well as from Computer Center of Kyushu University (Tadauchi, 1987, 1994, 1996, 2000; Tadauchi et al., 1999; Tadauchi \& Inoue, 2000a, b). The KONCHU (= insects in Japanese) is a taxon-based bibliographical entomology database based on main Japanese entomological and zoological journals. The present image database file HANABACHI (= bees in Japanese) is one of the KONCHU and a special file including detailed data of Japanese bees such as taxonomy, biology and distribution with various images of the body. Each record is composed of 16 items, i.e., scientific names (family, genus and species), Japanese name, distribution data, type locality, type depository, source of the original description, synonymy, morphological notes, remarks, flying season, visiting or associated flowers, natural enemy and various images. If a user clicks one of the images in the image menu, he or she can get the enlarged image and can examine detailed morphology. It is relatively difficult for non-specialists to identify some groups of bees. However it will be helpful for them to identify by using the images. They are essentially composed of the whole body, the head in frontal view, the mesoscutum, the propodeum, and the metasomal terga for each sex in this file. It is written mainly in English with Japanese and managed by a text database management system SIGMA working at a workstation in the Entomological Laboratory, Kyushu University.

The home page of the HANABACHI is presented in Figs. 1-3. The usage of the SIGMA system is explained in Arikawa et al. $(1987,1988)$.

\section{Acknowledgments}

We are grateful to Prof. Emeritus Y. Hirashima and Prof. J. Yukawa of Kyushu University and Prof. S. Arikawa, Head of the SIGMA Project Group of Kyushu University for their various help.

\section{References}

Arikawa, S. et al., 1987. [A text database management system SIGMA, Version 2]. Koho, Computer Center Kyushu Univ., 20: 517-581. (In Japanese.)

Arikawa, S. et al., 1988. SIGMA: A text database management system. RIFIS Techn. Rep. Res. Inst. Fundam. Inform. Sci., Kyushu Univ., CS-3: 1-16.

Hirashima, Y. (superviser), Entomological Laboratory, Faculty of Agriculture, Kyushu University and Japan Wild Life Research Center (eds.), 1989, 1990. A Check List of Japanese Insects. 1,767pp., Addenda and Corrigenda, 37pp., Fukuoka. (In Japanese.)

Tadauchi, O., 1987. [A public database of entomology KONCHU and its usage]. Koho, Computer Center Kyushu Univ., 20: 597-614. (In Japanese.) 


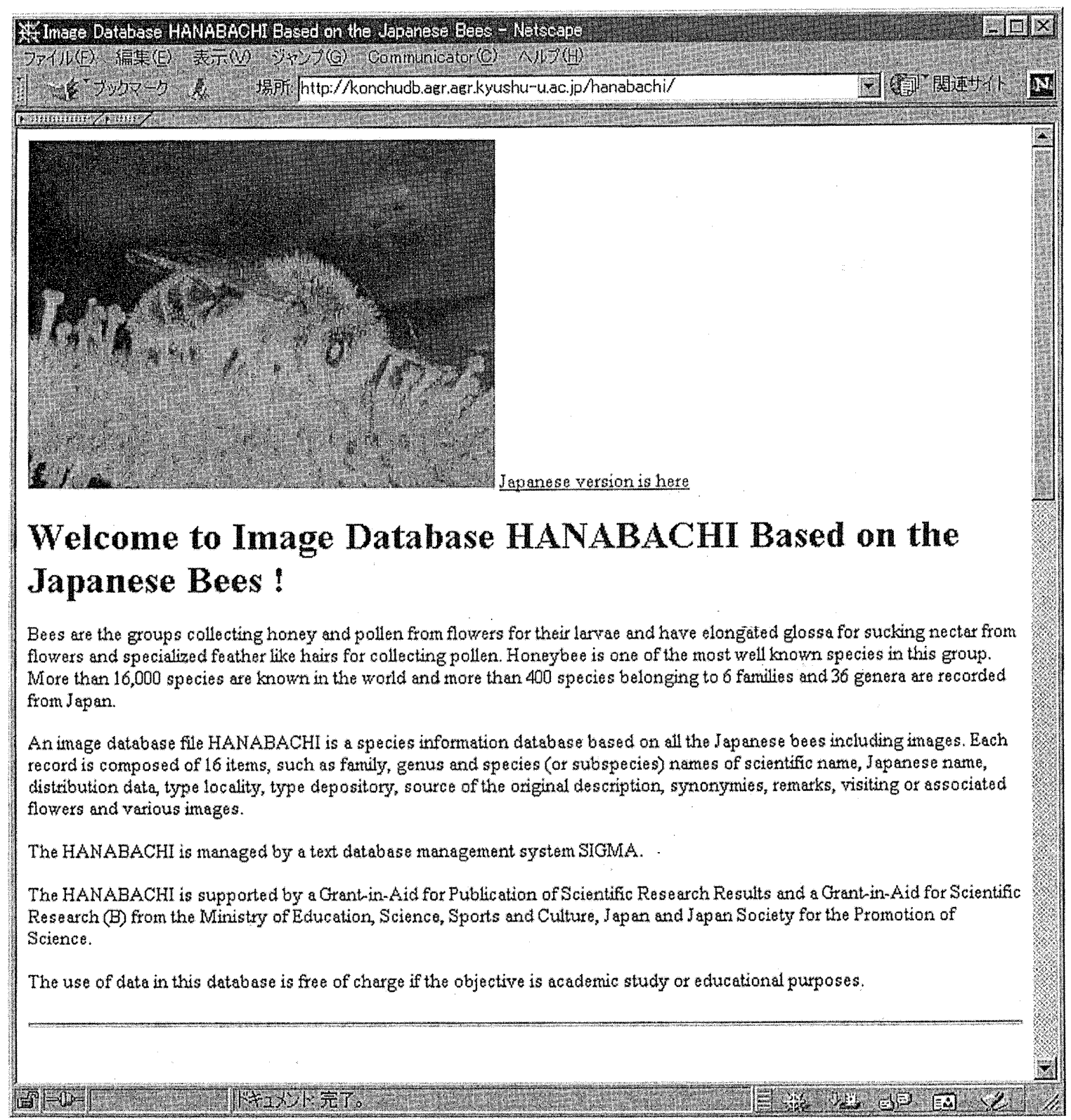

Fig. 1. A home page of an image database HANABACHI based on the Japanese bees in English version. A Japanese version is also available. 
- Search HANABACHI database

- How to Use

- Itenis of Data

- Example of a Record

- Copyright Notice

Inquiries and Comments

- Link

\section{Items of Data}

Data and Tags are the Following 16 items.

1. (FTAX) family (scientific name, including subfamily name)

2. (GTAX) genus (scientific name, including subgenus name)

3. (STAX) species (scientific name, including subspecies)

4. (JTAX) Japanese name

5. (DST) distribution (Japan inland; overseas)

6. (TYPE) type (sex)

7. (TYPEL) type locality

8. (TYPED) depository of the type

9. (DESC) source of the original description

10. (SYN) synonymy

11. (MOR) morphological notes

12. (REM) remarks

13. (FLY) flying season

14. (PL) visiting or associated flowers

15. (PAR) parasites

16. (IMG) images (total and partial images)

\section{Copyright Notice}

Entomology Database Project Group (Head: Osamu Tadauchi) holds the copyright on the entomology database. HANABACHI

\section{Inquiries and Comments}

Inquiries and Comments, about HANABACHI Should be the Following E-mail Address.

Database HANABACHI (Osamu Tadauchi)

Entomological Laboratory,

Faculty of Agriculture.

Kyushu University

Fukuoka, 812-8581

Japan

Phone: +81-92-642-2838 FAX: +81-92-642-2839

E-mail: tadauchi@agr.kyushu-u.ac.jp

\section{Link}

- Entomology Database KONCHU

- A Check List of Japanese Insects (MOKUROKU)

- Dictionary of Japanese Insect Names (DJD)

- Full Text Database ESAKIA file (Esakia, Kyushu University Publications in Entomology)(Japanese only)

Fig. 2. A home page of an image database HANABACHI in English version. Sixteen items are included in one record. 


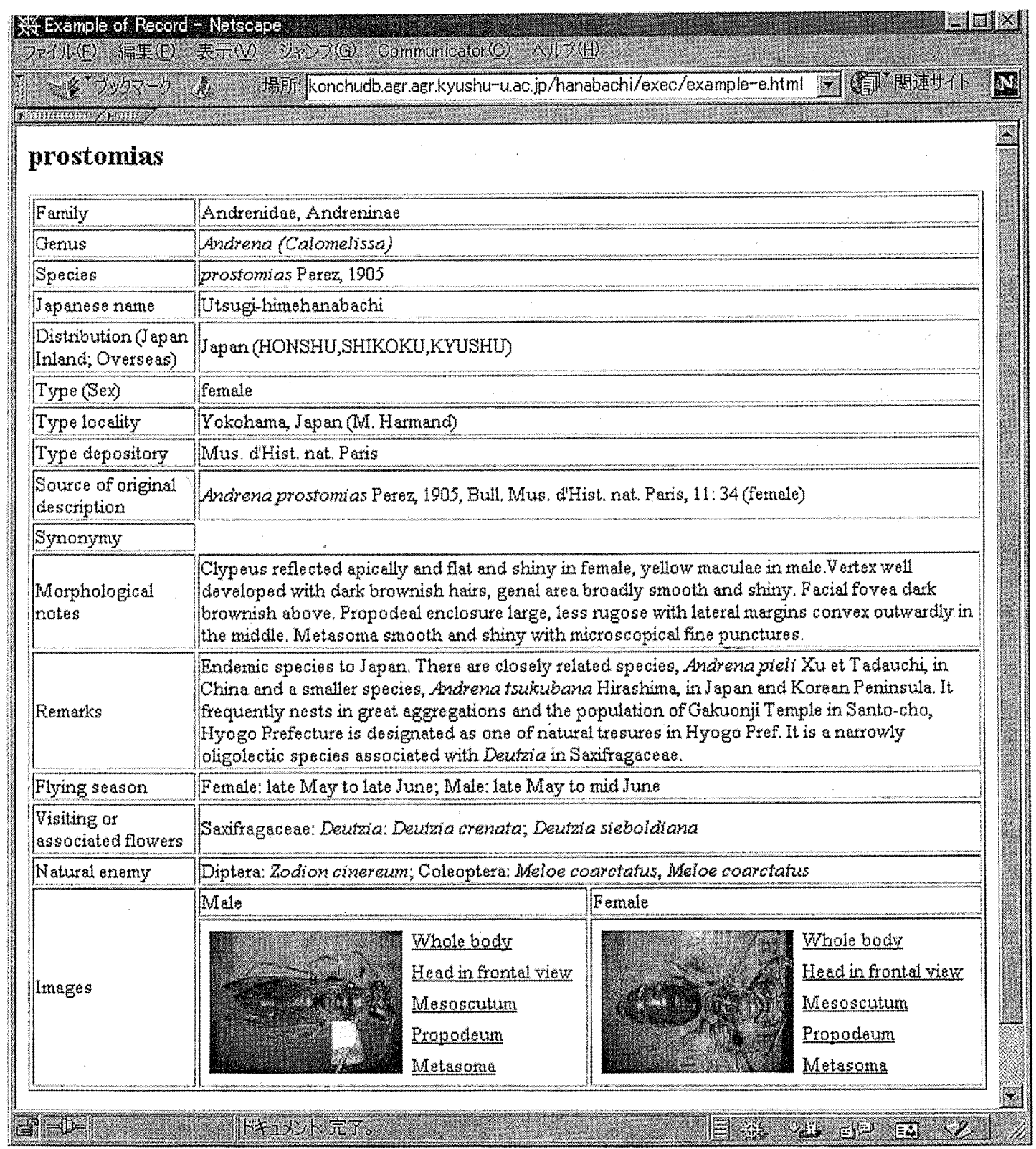

Fig. 3. Example of result of a search of the image database HANABACHI. This shows the data of Andrena prostomias. A user can examine enlarged images by selecting one of the lines in the image menu. 
Tadauchi, O. , 1994. ESAKIA file, one of the public taxon-based entomology database KONCHU produced at the Computer Center of Kyushu University. Esakia, (34): 227-237.

Tadauchi, O., 1996. [Database production of species information in insects]. pp. 156166, In Computer Center of Kyushu University (ed.), [Essays Contributed in Celebration of the 25th Anniversary of Computer Center of Kyushu University], Fukuoka. (In Japanese.)

Tadauchi, O., 2000. Species information database, KONCHU and MOKUROKU, on Japanese, East Asian and Pacific insects on Internet. pp. 49-62, In CODATA Korea Committee (KORDIC) (ed.) CODATA Korea 2000: Symposium on Biodiversity Information Network, Seoul.

Tadauchi, O. \& H. Inoue, 2000a. On MOKUROKU file based on "A Check List of Japanese Insects" on INTERNET. Esakia, (40): 81-84.

Tadauchi, O. \& H. Inoue, 2000b. On "Dictionary of Japanese Insect Names (DJI)" on INTERNET. Esakia, (40): 85-86.

Tadauchi, O., H. Inoue \& Y. Takematsu, 1999. Taxon-based entomology database KONCHU on INTERNET and its usage. Esakia, (39): 53-62. 